\title{
Interleukin-27 Early Impacts Leishmania infantum Infection in Mice and Correlates with Active Visceral Disease in Humans
}

OPEN ACCESS

Edited by:

Alexandre Morrot,

Federal University of

Rio de Janeiro, Brazil

Reviewed by:

Marisa Mariel Fernandez, University of Buenos Aires, Argentina

Celio Geraldo Freire De Lima, Federal University of

Rio de Janeiro, Brazi

Ricardo Fujiwara,

Universidade Federal de Minas

Gerais, Brazil

${ }^{*}$ Correspondence:

Anabela Cordeiro-da-Silva cordeiro@ibmc.up.pt

Specialty section: This article was submitted to Microbial Immunology, a section of the journal

Frontiers in Immunology

Received: 09 September 2016

Accepted: 20 October 2016

Published: 04 November 2016

Citation:

Pérez-Cabezas B, Cecílio $P$, Robalo AL, Silvestre R, Carrillo $E$,

Moreno J, San Martín JV, Vasconcellos $R$ and Cordeiro-daSilva A (2016) Interleukin-27 Early

Impacts Leishmania infantum Infection in Mice and Correlates with Active Visceral Disease in Humans.

Front. Immunol. 7:478.

doi: 10.3389/fimmu.2016.00478

\section{Begoña Pérez-Cabezas ${ }^{1,2}$, Pedro Cecílio ${ }^{1,2}$, Ana Luisa Robalo1,2, Ricardo Silvestre ${ }^{3,4}$ Eugenia Carrillo ${ }^{5}$, Javier Moreno ${ }^{5}$, Juan V. San Martín ${ }^{6}$, Rita Vasconcellos ${ }^{7}$ and Anabela Cordeiro-da-Silva ${ }^{1,2,8 *}$}

'i3S - Instituto de Investigação e Inovação em Saúde, Universidade do Porto, Porto, Portugal, ${ }^{2}$ IBMC - Instituto de Biologia Molecular e Celular, Universidade do Porto, Porto, Portugal, ${ }^{3}$ ICVS - Instituto de Investigação em Ciências da Vida e Saúde, Escola de Ciências da Saúde, Universidade do Minho, Braga, Portugal, "4CVS/3B's - Laboratório Associado, Braga, Portugal, ${ }^{5}$ WHO Collaborating Centre for Leishmaniasis, Centro Nacional de Microbiología, Instituto de Salud Carlos III, Madrid, Spain, ${ }^{6}$ Hospital Universitario de Fuenlabrada, Madrid, Spain, ${ }^{7}$ Departamento de Imunobiologia, Instituto de Biologia, Universidade Federal Fluminense, Niterói, Brazil, ${ }^{8}$ Faculdade de Farmácia, Departamento de Ciências Biológicas, Universidade do Porto, Porto, Portugal

The complexity of Leishmania-host interactions, one of the main leishmaniasis issues, is yet to be fully understood. We detected elevated IL-27 plasma levels in European patients with active visceral disease caused by Leishmania infantum, which returned to basal levels after successful treatment, suggesting this cytokine as a probable infection mediator. We further addressed this hypothesis recurring to two classical susceptible visceral leishmaniasis mouse models. BALB/c, but not C57BL/6 mice, showed increased IL-27 systemic levels after infection, which was associated with an upregulation of IL-27p28 expression by dendritic cells and higher parasite burdens. Neutralization of IL-27 in acutely infected BALB/c led to decreased parasite burdens and a transient increase in IFN- $\gamma^{+}$splenic $T$ cells, while administration of IL-27 to C57BL/6 promoted a local anti-inflammatory cytokine response at the site of infection and increased parasite loads. Overall, we show that, as in humans, BALB/C IL-27 systemic levels are infection dependently upregulated and may favor parasite installation by controlling inflammation.

Keywords: IL-27, Leishmania infantum, human, mouse models, immune regulation

\section{INTRODUCTION}

The 2013 Global Burden of Disease reveals leishmaniasis as one of the deadliest neglected tropical infectious diseases, affecting millions of people worldwide (1). It is caused by the sandfly transmitted protozoan parasite Leishmania. The infection can be asymptomatic or manifest in cutaneous, mucosal, and visceral forms, the last one being fatal if left untreated (2). These forms depend mostly on the infecting parasite species but also on the efficiency of the host immune response, especially during the first moments after parasite inoculation (3). Phagocytic cells are rapidly recruited upon Leishmania deposition in the skin by the sandfly, but the parasite is able to 
manipulate them using different strategies. One of the effects of this immunomodulation is the alteration of cytokines secretion in the infection microenvironment. Interferences with receptors and signaling pathways prevent the production and the function of pro-inflammatory cytokines such as IL-12 and IFN- $\gamma$ and favors anti-inflammatory IL-10 and TGF- $\beta$ contributing to parasite survival [reviewed in Ref. (4)].

Interleukin-27 is composed of the subunits p28 and EBVinduced protein 3 (EBI3) that interacts with a receptor comprising the glycoprotein 130 (gp130) and IL-27R $\alpha$ or WSX-1. Interleukin-27 is mainly produced by macrophages and dendritic cells (DCs) after the stimulation of surface receptors such as TLRs or CD40 and following IFNs signaling $(5,6)$. Although this cytokine was initially described as pro-inflammatory, numerous anti-inflammatory and immunomodulatory properties are recognized today [reviewed in Ref. $(5,6)$ ].

In the past few years, several reports have contributed to the understanding of the IL-27 role during Leishmania infection. Active visceral leishmaniasis (VL) patients from India (7) and Brazil (8) present increased IL-27 in plasma. In mice, IL-27 appears to be essential to prevent severe immunopathology after infection with both cutaneous (9) and visceral (10) strains, mainly through the effects of IL-10. However, whether IL-27 directly affects parasite burdens $(9,11)$ or if IL-10 appears as a consequence of inflammatory $(7,12)$ or suppressor (13) events is still unclear.

In the present study, we report elevated IL-27 plasma levels in Leishmania infantum-infected European patients with active VL, which normalized after successful treatment. Curiously, IL-27 increased early after L. infantum infection in the serum of $\mathrm{BALB} / \mathrm{c}$, but not in $\mathrm{C} 57 \mathrm{BL} / 6$ mice. We took advantage of this dichotomy to understand the mechanisms underlying the effects of IL-27 in visceral Leishmania infection. Early blocking of IL-27 in BALB/c mice decreased parasite loads, while IL-27 administration in C57BL/6 augmented parasite burdens. Immunological studies suggested that IL-27 is produced as a consequence of parasite subversion of the host immune response, resulting in a control of inflammation beneficial for parasite installation.

\section{MATERIALS AND METHODS}

\section{Ethics Statement}

Human sample collection was in accordance with Good Clinical Practice guidelines. The study was approved by the Ethics Committee of the University Hospital of Fuenlabrada (Madrid, Spain). All subjects provided their written informed consent.

Animal experiments were performed in accordance with the IBMC.INEB Animal Ethics Committees and the Portuguese National Authorities for Animal Health guidelines (directive 2010/63/EU). Begoña Pérez-Cabezas and Anabela Cordeiro-daSilva are accredited for animal research (Portuguese Veterinary Direction, Ministerial Directive 113/2013).

\section{Human Studies}

Diagnosed VL patients were treated with liposomal Amphotericin B (21 mg/kg). Cure was $100 \%$ in 3 months after diagnosis. Subjects without previous VL symptomology were included as negative controls. Plasma was recovered from heparinized blood and stored at $-20^{\circ} \mathrm{C}$ for posterior IL-27 determination using MILLIPLEX MAP (Millipore, Germany) and analyzed on a Bio-Plex-200 Luminex (Bio-Rad, CA, USA) (minimum detectable concentration $0.063 \mathrm{ng} / \mathrm{mL}$ ).

\section{Parasites and Mice}

A clone of virulent $L$. infantum (MHOM/MA/67/ITMAP263) was maintained by weekly subpassages at $26^{\circ} \mathrm{C}$ in RPMI 1640 medium supplemented with $10 \%$ heat-inactivated fetal bovine serum (FBS), $2 \mathrm{mM}$ L-glutamine, $100 \mathrm{U} / \mathrm{mL}$ penicillin, $100 \mathrm{microgram} / \mathrm{mL}$ streptomycin, and $20 \mathrm{mM}$ HEPES buffer (all from BioWhittaker, Lonza, Switzerland). Promastigotes from 4 to 10 passages were used in these experiments.

Six- to eight-week-old male $\mathrm{BALB} / \mathrm{c}$ and $\mathrm{C} 57 \mathrm{BL} / 6$ mice (Charles River Laboratories, France) were maintained under specific pathogen-free conditions at the IBMC facilities. Animals were infected i.p. with $1 \times 10^{8}$ stationary promastigotes from 5 culture days.

\section{Mice Sera Collection}

Blood from mice was collected through intracardiac puncture under isoflurane anesthesia. Serum was collected and stored at $-80^{\circ} \mathrm{C}$ for posterior analysis.

\section{Splenic Dendritic Cells and Macrophages Cell Sorting and Hepatic Kupffer Cell Enrichment Procedure}

Spleen and Liver were aseptically collected from $24 \mathrm{~h}$ infected mice. Splenocytes were obtained and labeled to distinguish DCs $\left(\mathrm{CD} 11 \mathrm{~b}^{+} / \mathrm{CD} 11 \mathrm{c}^{\text {high }}\right)$ and macrophages $\left(\mathrm{CD} 11 \mathrm{~b}^{+} / \mathrm{Ly} 6 \mathrm{G}^{-} / \mathrm{Ly} 6 \mathrm{C}^{+} /\right.$ $\mathrm{F} 4-80^{+}$), and sorted using a FACSAria and the FACSDiva software (BD Biosciences, NJ, USA) for posterior RNA analysis. Sorted cells purity was $>95 \%$.

Enriched Kupffer cells were obtained after hepatic collagenase digestion, followed by a Percoll density gradient centrifugation (Sigma-Aldrich, MO, USA) and a brief adhesion step, as described elsewhere (14). The percentage of Kupffer cells was determined by flow cytometry (F4/80+/CD $\left.11 b^{\text {variable }}\right)$. Cells were resuspended in lysis buffer and frozen for posterior RNA analysis.

\section{RNA Extraction and Quantitative RT-PCR}

Total RNA was extracted (RNeasy Mini Kit, Qiagen, CA, USA), quantified (NanoDrop1000, Thermo Scientific, MA, USA), and reversely transcribed (NZY-First-Strand cDNA synthesis Kit, NZYTech, Portugal). Quantitative RT-PCRs were run on an iQ5 iCycler thermal cycler (Bio-Rad) (15). Results were analyzed (built-in iQ5 v2, Bio-Rad) and normalized using the reference gene GAPDH. The sequences of the primers used were $I L-27 p 28$ Forward TCGATTGCCAGGAGTGAACC, Reverse CGAAG TGGTAGCGAGGAAG; EBI3 Forward AGCAGCAGCCTCC TAGCCT, Reverse ACGCCTTCCGGAGGGTC; and GAPDH Forward CTGGTCCTGAGTGTAGCCCAA, Reverse CATGGC CTTCCGTGTTCCTA. 


\section{In Vitro Differentiation and Infection of Bone Marrow-Derived DCs and Macrophages}

For bone marrow-derived DCs (BMDCs) differentiation, $6 \times 10^{6}$ bone marrow cells were seeded in $25 \mathrm{~mL}$ of complete RPMI supplemented with $50 \mu \mathrm{M}$ 2-mercaptoethanol (Sigma-Aldrich) and $10 \%$ of GM-CSF-containing supernatant from J558 cell conditioned medium (DC medium) (16). Cells were cultured at $37^{\circ} \mathrm{C}$ and $5 \% \mathrm{CO}_{2}$ for 3 days, after which the same amount of DC medium was added to each flask. At day 6, half of the culture supernatant was replaced with fresh DC medium. At day 8, cells were thoroughly resuspended, recovered, counted, and, finally, plated in 96 round-bottom culture plates at $1 \times 10^{5}$ cells/well in $200 \mu \mathrm{L}$ of DC medium. Bone marrow-derived macrophages (BMMØ) were obtained from non-adherent bone marrow cells collected after an initial overnight incubation $\left(37^{\circ} \mathrm{C}\right.$ and $5 \%$ $\mathrm{CO}_{2}$ ) in complete Dulbecco's modified Eagle's medium (DMEM) (Lonza). Non-adherent cells were counted and distributed in 96 flat-bottom well culture plates at $1 \times 10^{5}$ cells/well in $100 \mu \mathrm{L}$ of complete DMEM supplemented with 5\% of L-929 cell conditioned medium (LCCM). After 3 days of culture, $100 \mu \mathrm{L}$ of $\mathrm{DMEM}+5 \% \mathrm{LCCM}$ were added per well. Half of the media volume was renewed at day 6 of culture. BMM $\varnothing$ acquired a definitive differentiation status at day 8 .

Stationary promastigotes from 5 culture days (cultured as described in Section "Parasites and Mice") were added to BMDC or BMM $\varnothing$ at a 10:1 ratio. Non-internalized parasites were washed after $4 \mathrm{~h}$ incubation $\left(37^{\circ} \mathrm{C}\right.$ and $\left.5 \% \mathrm{CO}_{2}\right)$. Noninfected cells were stimulated with $1 \mu \mathrm{g} / \mathrm{mL}$ LPS (Sigma-Aldrich) as positive control, or received complete medium as negative control. Supernatants were recovered $24 \mathrm{~h}$ post-infection for cytokine quantification.

\section{In Vivo IL-27 Modulation}

Twenty-four hours after infection, BALB/c mice were i.p. treated with $20 \mu \mathrm{g}$ of goat anti-mouse IL-27p28 neutralizing antibody (a-IL-27) and C57BL/6 with $1 \mu \mathrm{g}$ of mouse recombinant IL-27 (rIL-27) (both from R\&D Systems), as previously reported $(17,18)$. As controls, BALB/c and C57BL/6 received $20 \mu \mathrm{g}$ of goat IgG (isotype control) and PBS (mock), respectively.

\section{Determination of Parasite Burdens}

Spleen and liver were aseptically collected, weighted, and disrupted. Splenic and hepatic parasite burdens were assessed by the limit dilution method. The parasite titer was considered as the last dilution with $>1$ motile parasite. The number of parasites per gram of organ was calculated, as discussed previously (19). Peritoneal cells were recovered and $2 \times 10^{5}$ cells from each exudate were subjected to cytospin in $200 \mu \mathrm{L}$ of PBS during $5 \mathrm{~min}$ at $1000 \mathrm{rpm}$ using a Shandon Cytospin II (GMI, MN, USA). Cell preparations were fixed with $2 \%$ paraformaldehyde (PFA) for $20 \mathrm{~min}$. Afterward, an adapted staining protocol was performed (20) by 2 min immersion in Kaplow modified solution, followed by $45 \mathrm{~s}$ immersions in Hemacolor reagent 1 and reagent 2 (Merk Millipore, Germany). Finally, slides were washed with distilled water, air dried, and observed by optical microscopy (100× magnification). For determination of the percentage of infected cells, 200 consecutive cells were differentially counted (infected versus non-infected) in 3 different areas of the same preparation and the mean of the 3 areas was calculated. The number of parasites per infected cells was assessed by counting 100 different infected cells from which the mean was calculated.

\section{Flow Cytometry}

The anti-mouse monoclonal antibodies used to perform this study were all purchased to BioLegend (CA, USA) except if otherwise stated: FITC-labeled anti-IgM (R6-60.2, BD Biosciences, NJ, USA), anti-MHC-II(I-Ad) (AMS-32.1, BD), anti-MHC-II(IA/I-E) (M5114.15.2), anti-IFN- $\gamma$ (XMG1.2), and anti-IL-17A (TC11-18H10.1); PE-labeled anti-CD8 (53-6.7, BD), anti-CD11b (M1/70), anti-Siglec-F (E50-2440, BD), anti-F4/80 (BM8), anti-IL-4 (11B11), and anti-IL-6 (MP5-20F3); PerCP-labeled anti-CD11b (M1/70); PerCP-Cy5.5-labeled anti-Ly6C (HK1.4), anti-F4-80 (BM8), and anti-TNF $\alpha$ (MP6-XT22); PE-Cy7-labeled anti-CD3 (HA2) and anti-CD11b (M1/70); APC-Cy7-labeled anti-CD11c (N418); APC-labeled anti-CD19 (6D5), anti-IL-5 (TRFK5), and anti-IL-10 (JES5-16E3); BV510-labeled anti-CD4 (RM4-5); and Pacific Blue ${ }^{\text {TM}}-$ labeled anti-Ly6G (1A8).

To analyze lymphoid and myeloid cell populations, two panels of antibodies were designed. The lymphoid panel was composed of anti-CD8, -CD3, -CD4, and -CD19. The Myeloid panel comprised anti-CD11b, -CD11c, -Siglec-F, -Ly6C, -Ly6G, and -MHC-II. Surface staining of peritoneal and splenic cells was performed in $\mathrm{PBS}+0.5 \% \mathrm{BSA}\left(20 \mathrm{~min}, 4^{\circ} \mathrm{C}\right)$ followed by $15 \mathrm{~min}$ fixation using $1 \%$ PFA. For intracellular staining, splenocytes were cultured for $2 \mathrm{~h}$ with PMA/Ionomycin $(50 / 500 \mathrm{ng} / \mathrm{mL})$ and then for $2 \mathrm{~h}$ with Brefeldin A $(10 \mu \mathrm{g} / \mathrm{mL})$. Cells were surface stained and then intracellularly after fixation and permeabilization with $1 \%$ saponin (all from Sigma) (21). Samples were acquired in a FACSCanto (BD) and analyzed using the FlowJo software v10 (TreeStar, OR, USA).

An initial gate plotting FSC-A versus SSC-A was performed. Afterward, singlets were selected by plotting FSC-A versus FSC-H and the remaining cell populations were resolved. $\mathrm{T}$ lymphoid cell populations were defined as $\mathrm{CD}^{+} / \mathrm{CD}^{+}$and $\mathrm{CD}^{+} / \mathrm{CD}^{+}$, while $\mathrm{B}$ cells were defined as $\mathrm{CD} 19^{+}$. Cytokine production by $\mathrm{T}$ cells was assessed within $\mathrm{CD} 3^{+} / \mathrm{CD}^{+}$and $\mathrm{CD} 3^{+} / \mathrm{CD} 8^{+}$cells. Myeloid cell populations were gated as eosinophils (Siglec- $\mathrm{F}^{+}$/ SSC- $\mathrm{H}^{\text {int/high }}$ ), neutrophils (CD11 $\mathrm{b}^{\text {high }} / \mathrm{Ly}_{6} \mathrm{G}^{\text {high }} /$ Siglec- $\mathrm{F}^{-}$), DCs $\left(\mathrm{CD} 11 \mathrm{c}^{+} / \mathrm{MHC}-\mathrm{II}^{\mathrm{int} / \mathrm{high}}\right)$, and macrophages $\left(\mathrm{CD} 11 \mathrm{~b}^{+} / \mathrm{CD}_{11 \mathrm{c}^{-} /}\right.$ ${\text { Ly } 6 \mathrm{G}^{-} / \text {Siglec- }}^{-}$).

\section{Determination of Mouse Cytokines by ELISA}

Cytokines were quantified, according to the manufacturer's instructions, using the commercial kits: IL-27 ELISA ReadySET-Go! ${ }^{\circledR}$ (eBiosciences, CA, USA) (detection limit $16 \mathrm{pg} /$ mL); IL-27p28/IL-30 and IL-10 DuoSet ELISA (R\&D Systems, $\mathrm{MN}, \mathrm{USA}$ ) (detection limits 15.6 and $31.2 \mathrm{pg} / \mathrm{mL}$, respectively); IL-12p70 and IFN- $\gamma$ ELISA MAX Deluxe (BioLegend, CA, USA) (detection limit $4 \mathrm{pg} / \mathrm{mL}$ for both cytokines). 


\section{Statistical Analysis}

Results are expressed as mean \pm SEM. Statistical differences were analyzed using GraphPad Prism v6.01 (CA, USA). Comparisons between human samples were performed using Mann-Whitney test for unpaired samples and Wilcoxon test for paired data. Mice experimental groups were compared using the unpaired $t$-test unless otherwise stated.

\section{RESULTS}

\section{Systemic IL-27 Increases in L. infantum-Infected European Patients and BALB/c Mice}

To address if the increase of systemic IL-27 is a common fact of VL among different endemic areas $(7,8)$, we determined this cytokine in the plasma of active L. infantum infected individuals from a current outbreak in Spain. Patients with active disease presented higher IL-27 levels than both cured $(p \leq 0.001)$ and negative controls $(p \leq 0.001)$ (Figure 1A). Some patients were re-sampled after cure, which confirmed that IL-27 decreases after successful treatment $(p \leq 0.01)$ (Figure 1A).

The role of IL-27 during Leishmania infection was addressed using mouse models by several authors (10-13, 22). However, whether IL-27 is also increased in the serum of Leishmaniainfected mice has never been shown. Therefore, we addressed if $\mathrm{BALB} / \mathrm{c}$ and $\mathrm{C} 57 \mathrm{BL} / 6$, two susceptible VL mouse species, displayed a similar systemic increase of IL-27 as observed in L. infantum-infected humans. While IL-27 remained unchanged in the serum of infected C57BL/6 mice, infected BALB/c showed an early increase that was significant 4 days after infection ( $p \leq 0.05)$ and always higher than the IL-27 levels of C57BL/6 mice ( $p \leq 0.05$ comparing the day 2 and $p \leq 0.01$ the day 4 after infection) (Figure 1B).

\section{Dendritic Cells Are the Main Cellular Source of IL-27 in Infected BALB/c Mice}

As the main sources of IL-27 are myeloid cell populations, and macrophages and DCs play critical roles during Leishmania infection, we decided to discriminate their contribution to IL-27 response after L. infantum infection. For that, the expression of IL-27 subunits in splenic DCs and macrophages sorted from infected BALB/c and C57BL/6 was evaluated. While the expression of EBI3 remained always comparable to basal levels (Figure S1 in Supplementary Material), IL-27p28 expression was significantly upregulated but only in DCs from BALB/c $24 \mathrm{~h}$ after infection $(p \leq 0.05)$ (Figure 2A). The contribution of Kupffer cells, the resident liver macrophages, for the IL-27 response to $L$. infantum was also addressed. The expression of IL-27 subunits was analyzed in Kupffer cells from noninfected and infected $\mathrm{BALB} / \mathrm{c}$ mice. However, no increase in the RNA levels of IL-27p28 and EBI3 was detected in these cells $24 \mathrm{~h}$ after infection (Figure S2 in Supplementary Material), suggesting that DCs, and not macrophages, are the main cell source responsible for the increase of IL-27 in our model.

To confirm our data at protein level, we determined IL-27 and IL-27p28 in supernatants from $24 \mathrm{~h} \mathrm{~L}$. infantum-infected BMM $\varnothing$ and BMDCs. Although after infection the production of IL-27p28 was greater in BMM $\varnothing$ from C57BL/6 than from BALB/c $(p \leq 0.05)$, IL-27 concentration was similar in both mouse strains. No difference was found after LPS activation (Figure 2B). In line with ex vivo results, both IL-27p28 and IL-27 secretion by BMDCs were significantly higher in cells
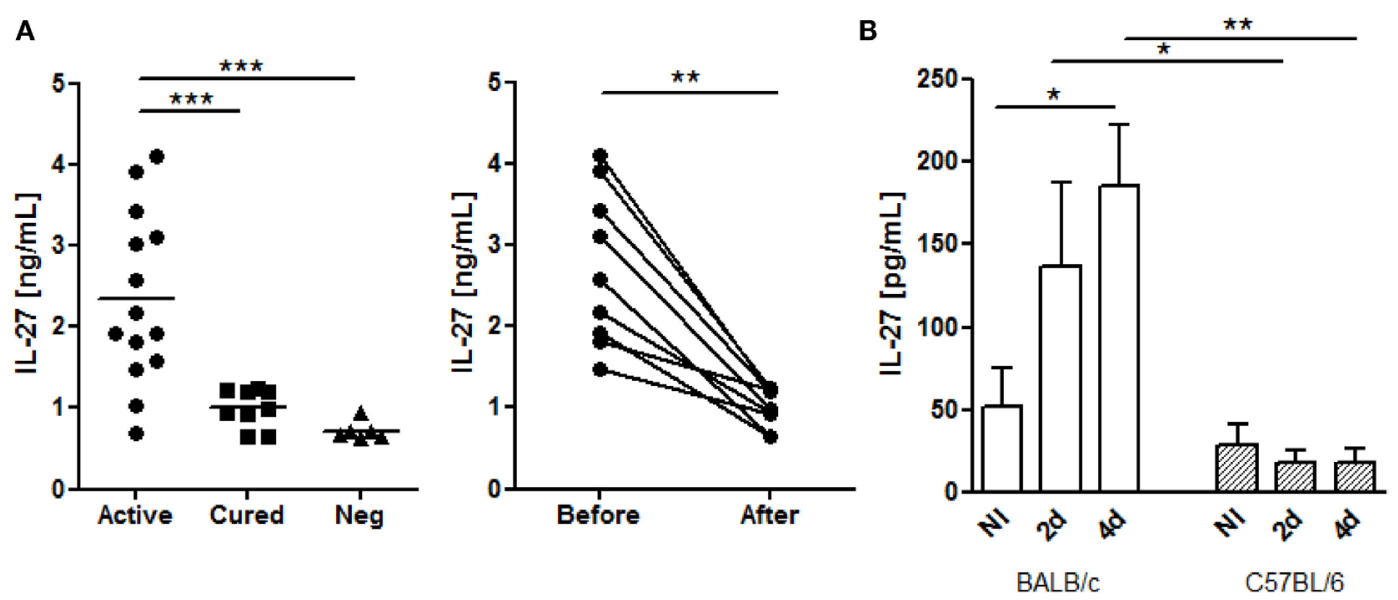

FIGURE $1 \mid$ L. infantum infection increases systemic IL-27 in European VL patients and in BALB/c mice. (A) Interleukin-27 levels in the plasma of European patients with active VL caused by L. infantum (black dots, $n=14$ ), cured patients (black squares, $n=9$ ), and negative controls (black triangles, $n=6$ ). The cytokine was also determined in VL patients before and after treatment $(n=9)$. Each symbol represents one individual; bars represent the mean of the experimental groups. Mann-Whitney test was used to compare clinical groups and Wilcoxon matched pairs test for paired comparisons. (B) Interleukin-27 levels in the serum of BALB/c (white columns) and C57BL/6 (patterned columns) mice, infected i.p. with $1 \times 10^{8} \mathrm{~L}$. infantum promastigotes for 2 and 4 days. Bars represent mean \pm SEM of three independent experiments with a minimum of four animals per group and experiment. Unpaired $t$-test was used to assess statistical significances $\left({ }^{\star} p \leq 0.05,{ }^{* *} p \leq 0.01\right.$, and $\left.{ }^{* \star *} p \leq 0.001\right)$. 
A

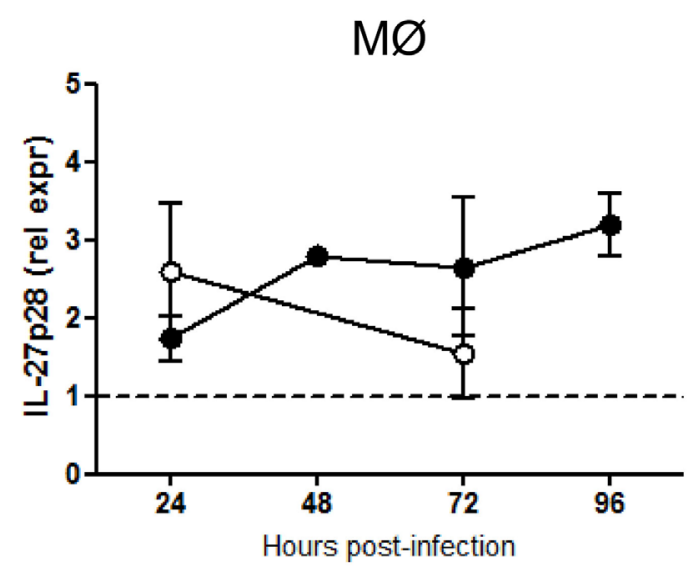

B

BMMØ
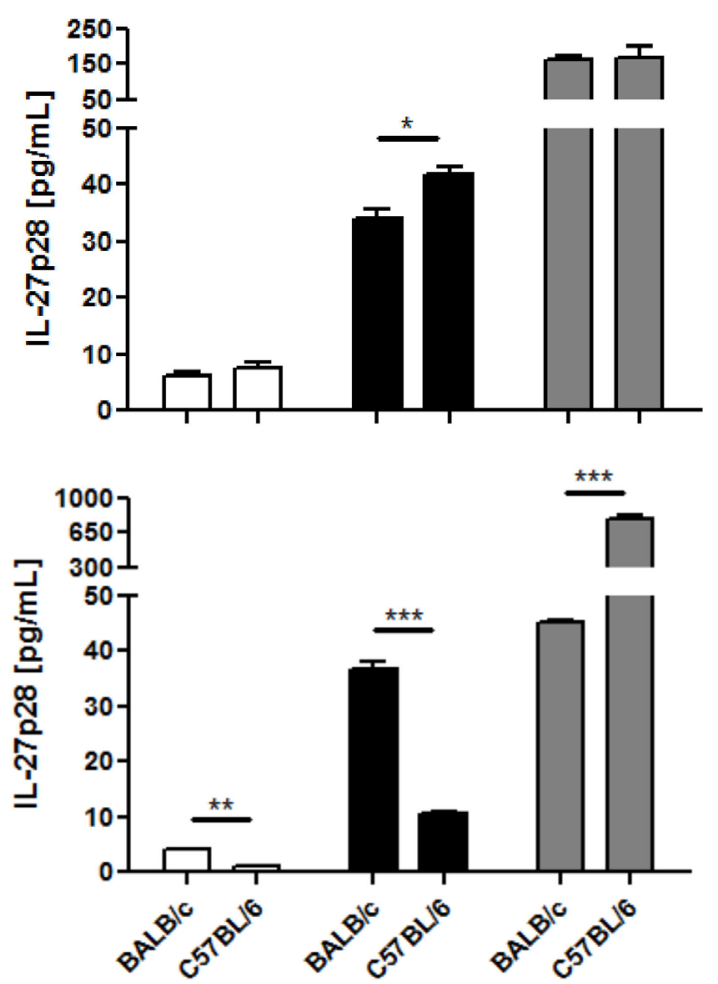
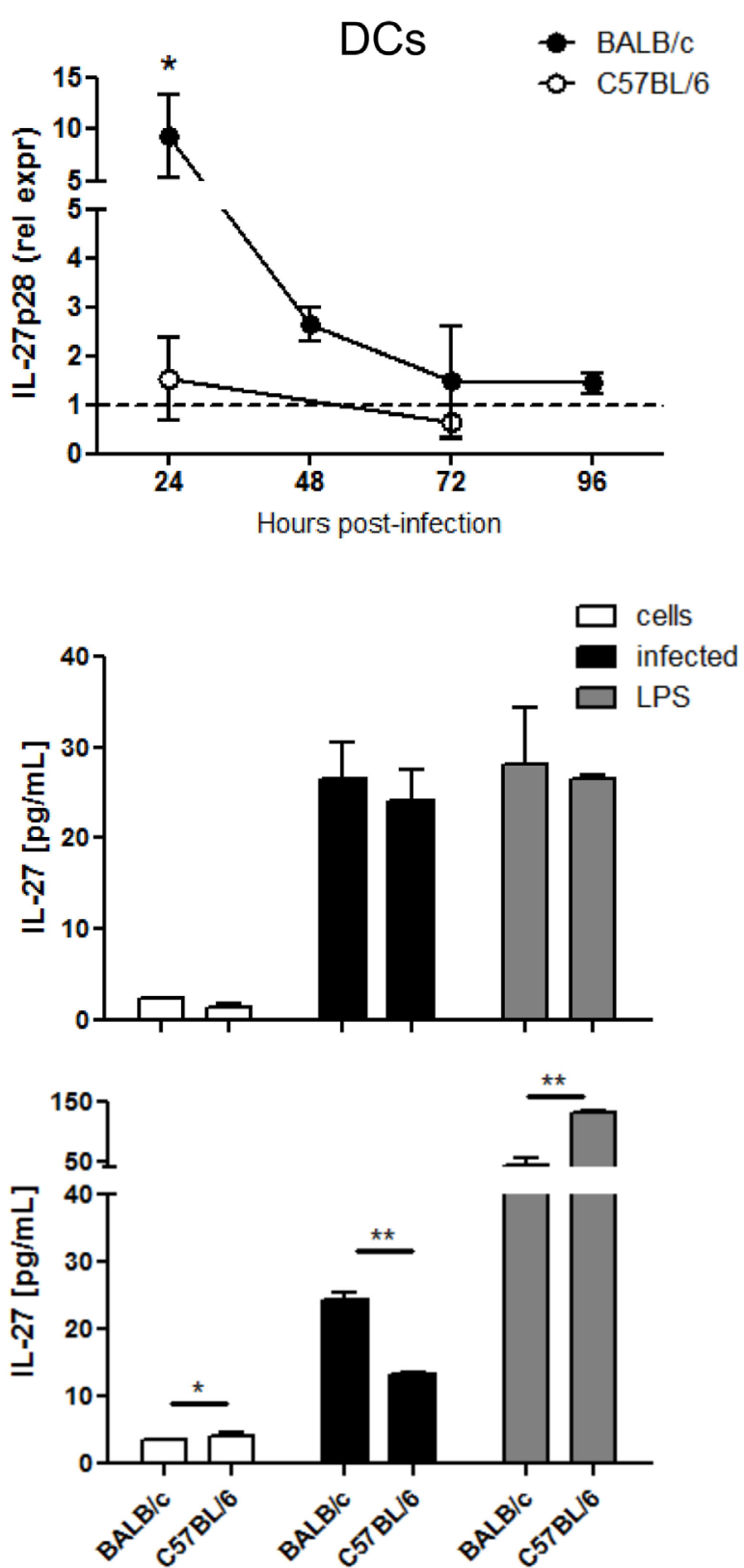

FIGURE 2 | Dendritic cells are the main source of IL-27 after L. infantum infection in BALB/c mice. (A) Splenic MØ and DCs were sorted from infected BALB/c (black symbols) and C57BL/6 (open symbols) mice at the indicated time points. The transcription levels of IL-27p28 were quantified by qRT-PCR. Results are relativized to non-infected mice values $(=1)$. Every symbol and bars represent the mean and SEM, respectively, of four different animals per group analyzed in two different independent experiments. Unpaired $t$-test was used to assess statistical significances. (B) The secretion of IL-27p28 and IL-27 was quantified by ELISA in $24 \mathrm{~h}$ supernatants of BMM $\varnothing$ and BMDC infected with L. infantum promastigotes at a 1:10 ratio (black bars). Medium (white bars) and LPS (gray bars) were used as negative and positive controls, respectively. Bars represent the mean \pm SEM of two independent experiments, every run in duplicate. Unpaired $t$-test was used to assess statistical significances $\left({ }^{*} p \leq 0.05,{ }^{* *} p \leq 0.01\right.$, and $\left.{ }^{* \star *} p \leq 0.001\right)$.

from $\mathrm{BALB} / \mathrm{c}$ when compared to $\mathrm{C} 57 \mathrm{BL} / 6(p \leq 0.001$ and $p \leq 0.01$, respectively) (Figure 2B). Interestingly, the ability of BMDCs to produce both cytokines after LPS stimulation was higher in $\mathrm{C} 57 \mathrm{BL} / 6$ than in $\mathrm{BALB} / \mathrm{c}$, indicating that these cells are really capable of producing IL-27, but not in response to $L$. infantum infection. These results suggest that the parasite can actively modulate the secretion of IL-27 and
IL-27p28 in BMDCs obtained from BALB/c, but not from C57BL/6 mice.

\section{IL-27 Favors $L$. infantum Infection in Mouse Models}

To determine whether IL-27 contribute to the infection outcome, we neutralized IL-27 in BALB/c and administered 
A

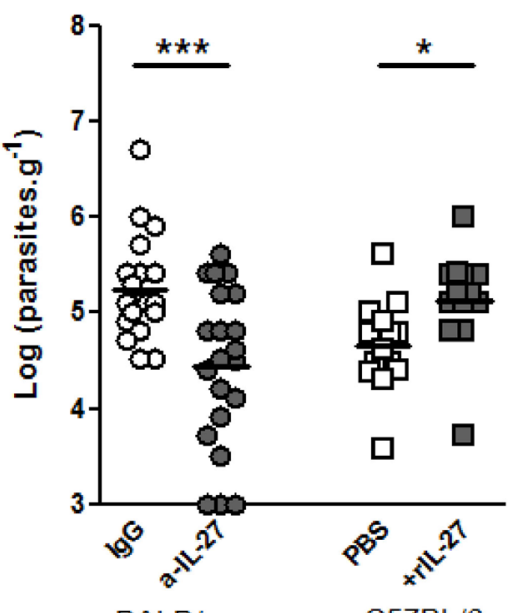

$\mathrm{BALB} / \mathrm{C}$
Spleen

C57BL/6

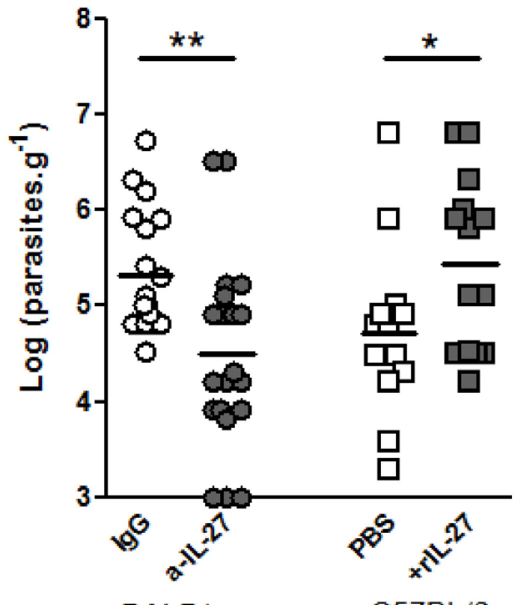

$\mathrm{BALB} / \mathrm{C}$

C57BL/6

B

Peritoneal cavity
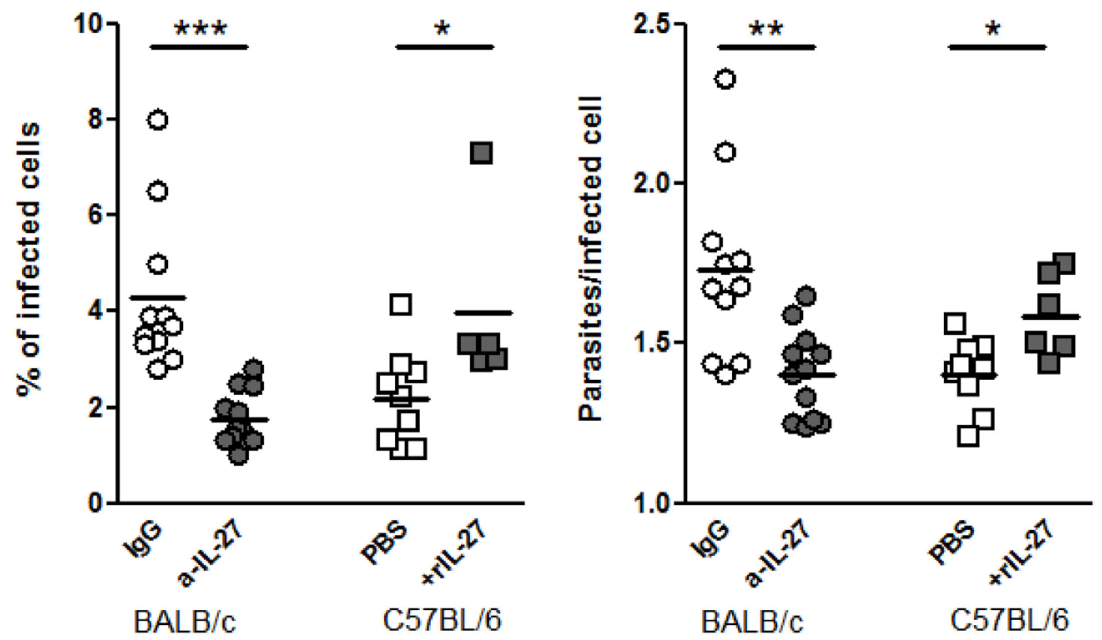

FIGURE 3 | IL-27 favors $\mathbf{L}$. infantum infection in mice models. (A) BALB/c (circles) and C57BL/6 (squares) mice were i.p. infected with $1 \times 10^{8}$ promastigotes. Twenty-four hours later, BALB/c mice were treated i.p. with $20 \mu \mathrm{g}$ of a-IL-27 (gray circles) or lgG isotype control (open circles), while C57BL/6 received i.p. $1 \mu \mathrm{g}$ of mouse rlL-27 (gray squares) or the same volume of PBS (open squares). Three days after treatment, mice were euthanized and the parasite load of spleen and liver determined by limiting dilution. (B) In some animals, the peritoneal cavity was washed for collection of recruited cells. Approximately $2 \times 10^{5}$ cells from every exudate were cytospined, fixed, and stained with Kaplow modified solution and by the Giemsa method. Finally, slides were observed by optical microscopy at $100 \times$ for determination of the percentage of infected cells and the number of parasites/infected cell. All data represent results obtained in three independent experiments. Every symbol represents a mouse and the bars the mean of the group. Unpaired $t$-test was used to assess statistical significances ( ${ }^{*} p \leq 0.05$,

${ }^{* *} p \leq 0.01$, and $\left.{ }^{* * *} p \leq 0.001\right)$.

rIL-27 to C57BL/6 mice $24 \mathrm{~h}$ after infection, coinciding with the IL-27p28 RNA peak in the spleen and before the IL-27 increase observed in the serum, 2 days after the infection, in $\mathrm{BALB} / \mathrm{c}$ mice. Seventy-two hours later, these treatments significantly decreased in $\mathrm{BALB} / \mathrm{c}$ and increased in $\mathrm{C} 57 \mathrm{BL} / 6$ splenic and hepatic parasite burdens (Figure 3A). We also observed that IL-27 significantly affected the percentage of infected cells and the number of parasites per infected cells in the peritoneal cavity (Figure 3B). These results revealed a relation between the levels of IL-27 and the establishment of the infection.

\section{IL-27 Modulates the Cytokine Response in Infected Mice}

To elucidate how IL-27 interferes at the early stages of L. infantum infection, we performed a kinetic study of the peritoneal and splenic compartments after IL-27 modulation. Interestingly, IL-27 neutralization in infected BALB/c mice 
transiently decreased IL-10 in the peritoneal cavity $(p \leq 0.01)$, and the administration of rIL-27 increased the presence of this cytokine in infected C57BL/6 mice $24 \mathrm{~h}(p \leq 0.01)$ and $72 \mathrm{~h}(p \leq 0.05)$ after treatment, always comparing with control infected animals (Figure 4). In addition, rIL-27 in C57BL/6 promoted a reduction of IFN- $\gamma(p \leq 0.05)$ and IL-12p70 $(p \leq 0.01) 24 \mathrm{~h}$ after treatment in comparison with infected non-treated animals (Figure 4). However, this shift in the cytokine profile determined by IL-27 almost did not alter cell recruitment to the site of infection, as when comparing treated and non-treated animals only the presence of B cells in the peritoneal cavity significantly increased $72 \mathrm{~h}$ after IL-27 blockage in BALB/c mice (Figure 5). In the spleen, the number of $\mathrm{CD}^{+} \mathrm{T}$ cells increased in BALB/c mice $24 \mathrm{~h}$ after IL-27 blockage $(p \leq 0.05)$, and the supply of the cytokine decreased the presence of the same cells in C57BL/6 mice after $72 \mathrm{~h}$ ( $p \leq 0.05$ ) (Figure 5). The administration of rIL-27 also prevented the infiltration of neutrophils in the spleen of C57BL/6 mice $(p \leq 0.01)$ (Figure 6). Analysis of the cytokine production revealed that IL-27 neutralization increased the numbers of IFN- $\gamma$ producing $\mathrm{CD}^{+}$and $\mathrm{CD}^{+} \mathrm{T}$ cells $24 \mathrm{~h}$ post-treatment (Figure 7$)(p \leq 0.01)$. These differences were not detected at $72 \mathrm{~h}$, likely indicating a reversible effect (Figure 7). The potential secretion of other cytokines was also analyzed but no differences between $\alpha$-IL-27 and IgG receiving mice were observed (Figure S3 in Supplementary Material). In contrast, rIL-27 did not alter the cytokine response of C57BL/6 splenic $\mathrm{T}$ cells (Figure 7; Figure S3 in Supplementary Material).

\section{DISCUSSION}

Interleukin-27 is a cytokine with known immunomodulatory properties involved in the pathogenesis of numerous diseases $(5,6)$. Several types of infections also course with an increase of IL-27 (23-25). However, whether this fact is a simple host mechanism to control inflammation or a complex pathogen evasion strategy is still unknown. Leishmania spp. are expert in modulating immune activity through diverse strategies (4). Previous reports on human leishmaniasis indicate that IL-27 increases when the disease is active in both cutaneous (26-28) and visceral forms $(7,8)$. Here, for the first time, plasma levels of IL-27 were evaluated in L. infantum-infected individuals from Europe. This cytokine was significantly increased in the active phase of our VL patients returning to homeostatic levels after treatment. Interestingly, a relapsing case presented increased circulating IL-27, and positive IL-27 results were obtained even when immunofluorescence antibody test (IFAT) was doubtful (data not shown). Further analysis using a larger cohort of patients will help to better understand the value of IL-27 as a complementary biomarker for human VL diagnosis and even for treatment efficacy monitoring, as has been postulated for this disease (8) and other infections (29).

The role of IL-27 during Leishmania infection has been addressed using animal models by several groups $(9,10,12,30)$. The general conclusion was that IL-27 controls inflammation and pathology through limitation of IFN- $\gamma$ (12) and IL-17 (9) production by $\mathrm{CD} 4^{+} \mathrm{T}$ cells, resulting in a permissive environment for the infection. However, these results are based on experiments performed on WSX-1 $1^{-l-}$ or $\mathrm{EBI}^{-/-}$mice, presenting two main limitations. First, both WSX-1 and EBI3 are subunits shared with the regulatory cytokine IL-35 (31), meaning that the over-inflammation observed in these knockout mice can be a result of the additive loss of the regulatory function of both cytokines. The second issue is that both mice models were generated in the $\mathrm{C} 57 \mathrm{BL} / 6$ genetic background. Although both $\mathrm{C} 57 \mathrm{BL} / 6$ and $\mathrm{BALB} / \mathrm{c}$ strains are considered susceptible models for experimental VL (32), here we showed that only BALB/c and not C57BL/6 mice increased IL-27 in the serum early

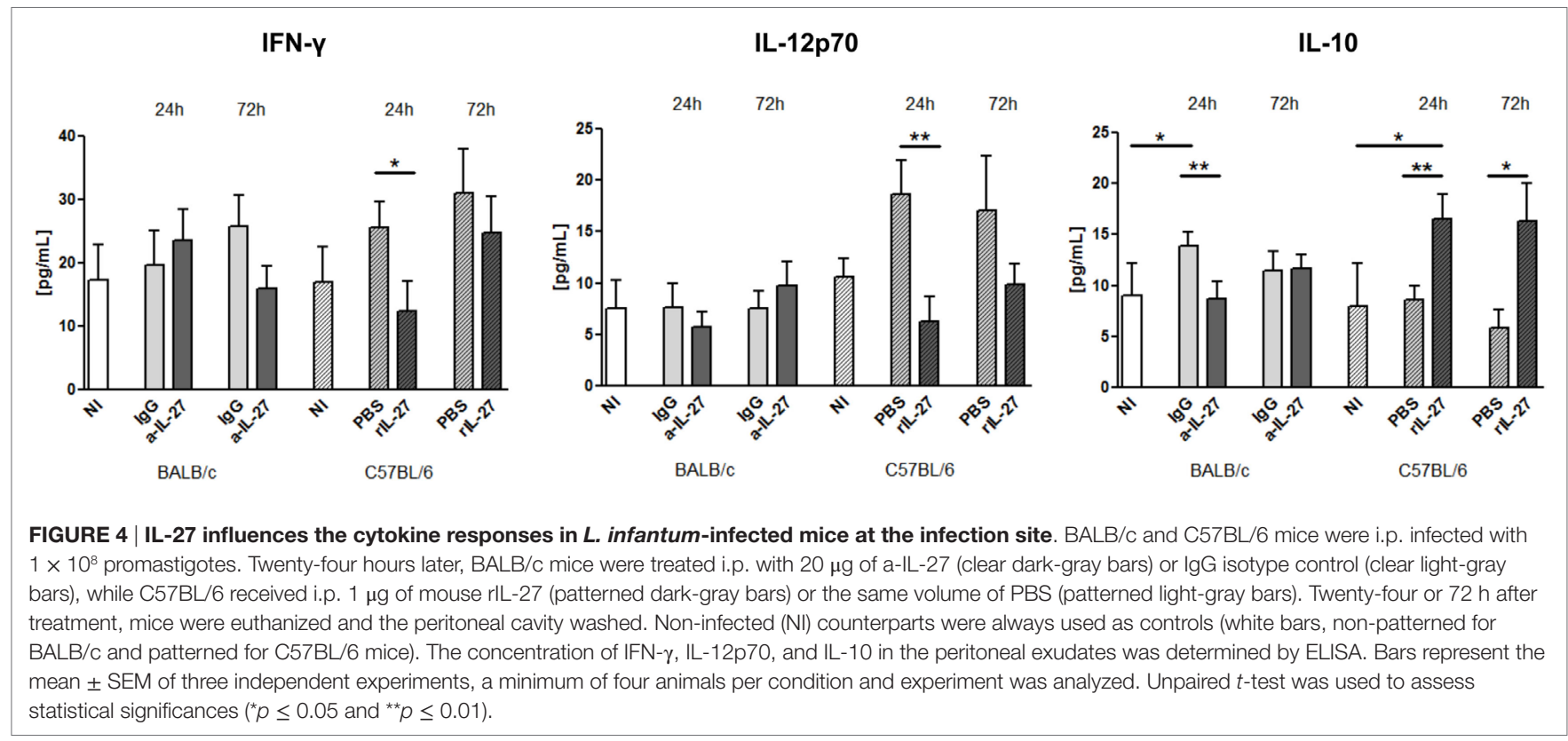



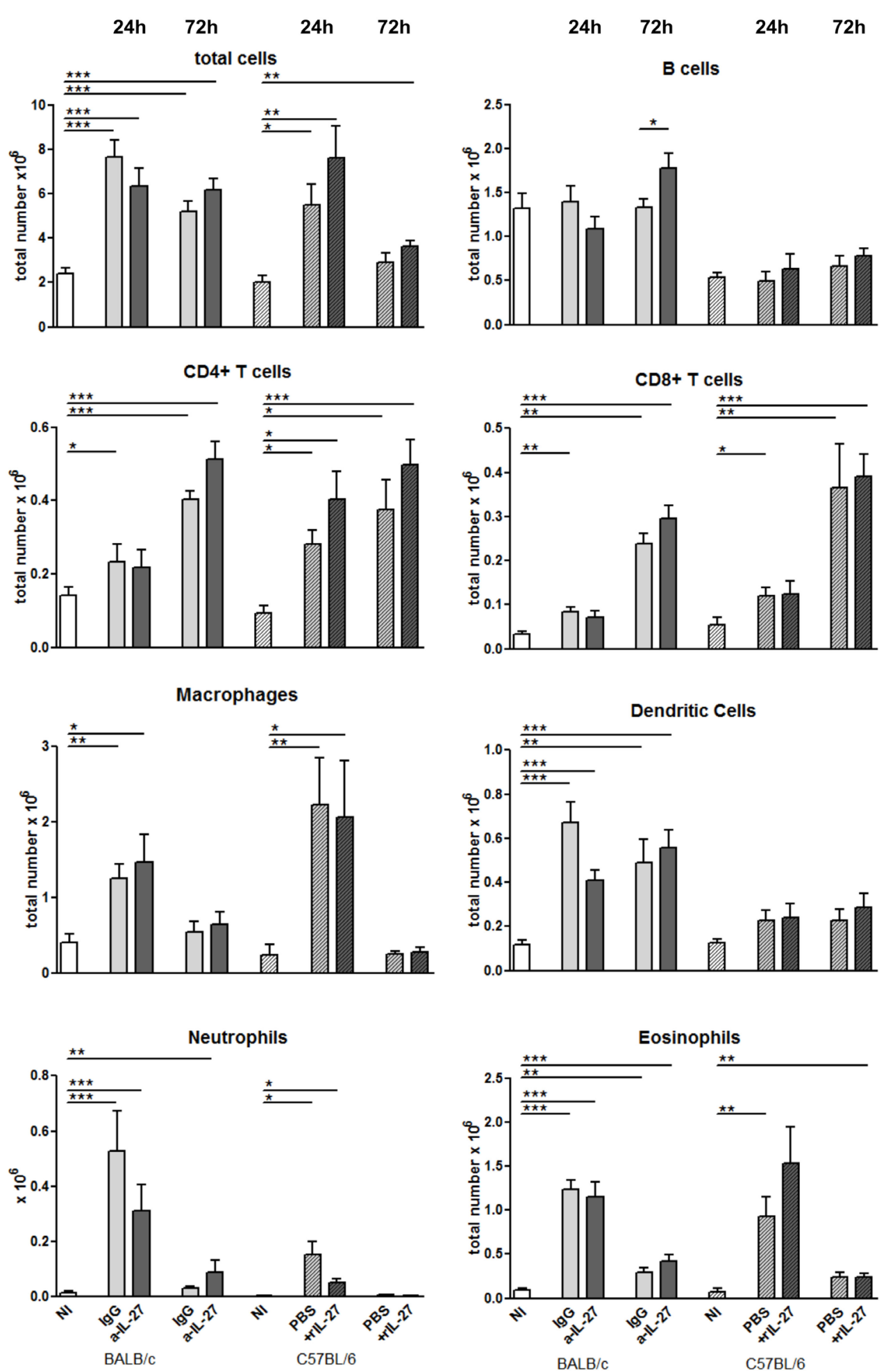

FIGURE 5 | Cell recruitment to the peritoneal cavity in response to $\mathbf{L}$. infantum infection after IL-27 modulation. BALB/C and C57BL/6 mice were i.p. infected with $1 \times 10^{8}$ promastigotes. Twenty-four hours later, BALB/c mice were treated i.p. with $20 \mu \mathrm{g}$ of a-IL-27 (clear dark-gray bars) or lgG isotype control (clear light-gray bars), while C57BL/6 received i.p. $1 \mu \mathrm{g}$ of mouse rIL-27 (patterned dark-gray bars) or the same volume of PBS (patterned light-gray bars). Twenty-four or $72 \mathrm{~h}$ after treatment, mice were euthanized and the peritoneal cavity washed. Non-infected (NI) counterparts were always used as controls (white bars, nonpatterned for BALB/c and patterned for C57BL/6 mice). Peritoneal cells were then extracellularly stained and acquired by flow cytometry. Bars represent the mean \pm SEM of three independent experiments, a minimum of four animals per condition and experiment was analyzed. Unpaired $t$-test was always used to assess statistical significances $\left({ }^{\star} p \leq 0.05,{ }^{\star \star} p \leq 0.01\right.$, and $\left.{ }^{\star \star *} p \leq 0.001\right)$. 


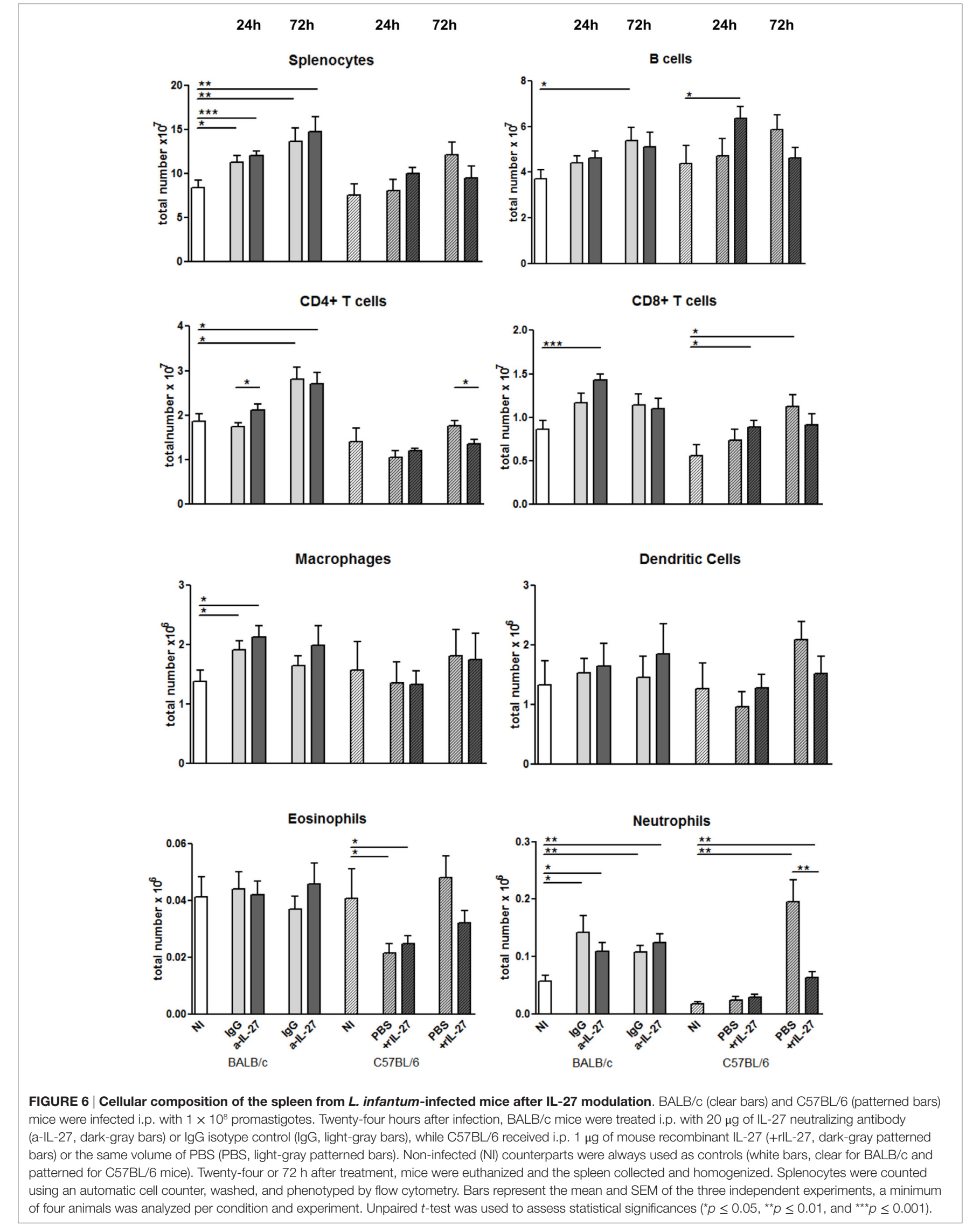



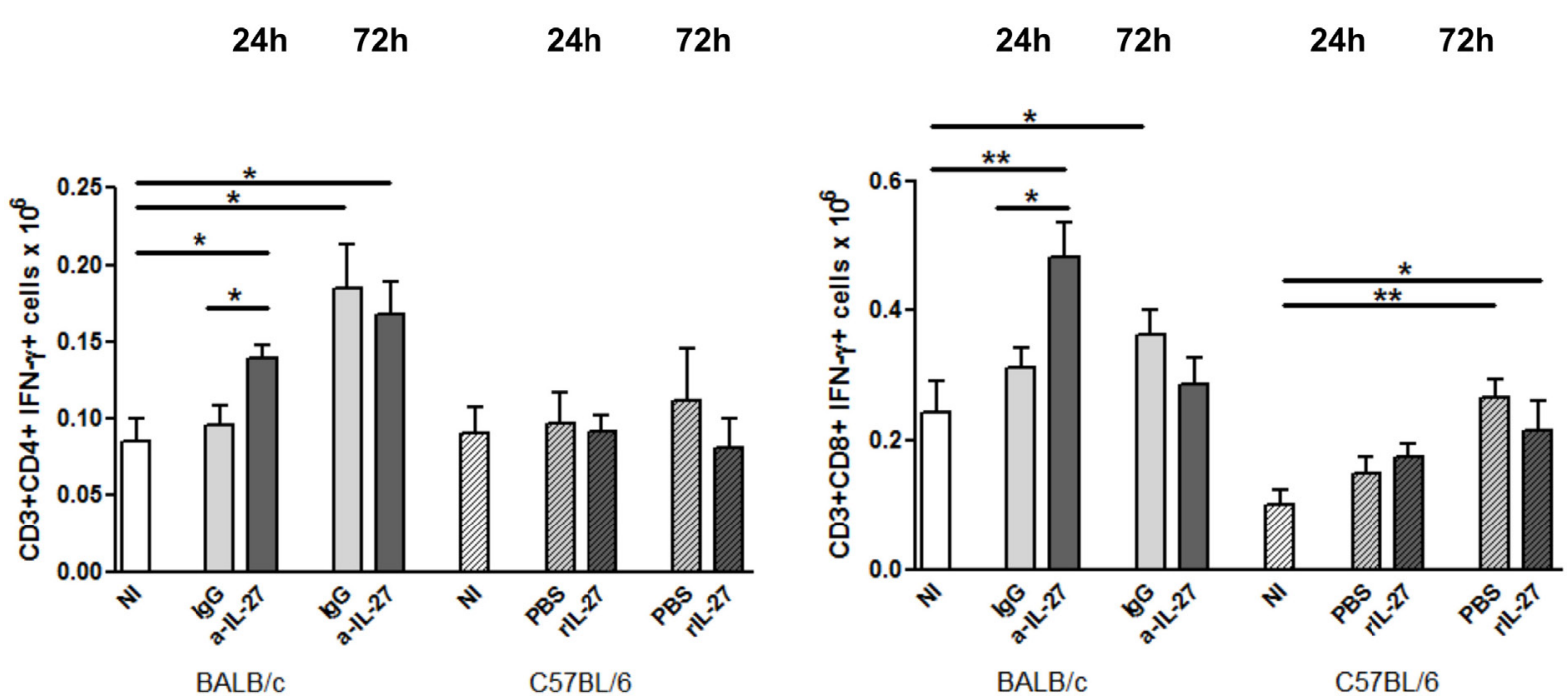

FIGURE 7 | IL-27 neutralization increases the IFN- $\gamma$ response of splenic T cells in BALB/c mice (clear bars) and C57BL/6 (patterned bars) mice were infected i.p. with $1 \times 10^{8}$ promastigotes. Twenty-four hours after infection, BALB/c mice were treated i.p. with $20 \mu \mathrm{g}$ of IL-27 neutralizing antibody (a-IL-27, dark-gray bars) or lgG isotype control (IgG, light-gray bars), while C57BL/6 received i.p. $1 \mu \mathrm{g}$ of mouse recombinant IL-27 (+rlL-27, dark-gray patterned bars) or the same volume of PBS (PBS, light-gray patterned bars). Non-infected (NI) counterparts were always used as controls (white bars, clear for BALB/c and patterned for C57BL/6 mice). Twenty-four or $72 \mathrm{~h}$ after treatment, mice were euthanized and the spleen collected and homogenized. Splenocytes were counted with an automatic cell counter, washed, and in vitro cultured during $4 \mathrm{~h}$ in the presence of PMA + lonomycin and Brefeldin A. Cells were then extra- and intracellularly stained and acquired by flow cytometry. Bars represent the mean and SEM of the three independent experiments, a minimum of four animals was analyzed per condition and experiment. Unpaired $t$-test was used to assess statistical significances $\left({ }^{*} p \leq 0.05\right.$ and $\left.{ }^{* *} p \leq 0.01\right)$.

after i.p. infection with $L$. infantum. The difference observed in the IL-27 production between the two mice strains in this study was confirmed at the cellular level, as splenic DCs from $\mathrm{BALB} / \mathrm{c}$ but not from $\mathrm{C} 57 \mathrm{BL} / 6$ mice upregulated the expression of IL-27p28 after infection. Upregulation of IL-27p28 in splenic DCs from BALB/c mice was previously shown after i.v. infection with Leishmania donovani, being $\mathrm{CD} 8 \alpha^{+}$DCs the major responsible subset (22). The production of IL-27 could restrict the typical Th1 polarization induced by these APCs, known to be essential for parasite limitation (33). In fact, in a conditional IL-27p28 knockout mice model restricted to DCs, $\mathrm{CD} 4^{+} \mathrm{T}$ cell IFN- $\gamma$ response was exacerbated (34). Our data suggest that DCs are the main cell source responsible for the increase of IL-27 in BALB/c mice early after L. infantum infection probably as a result of active cell function modulation by the parasite. One explanation for the IL-27 divergence observed between the mice strains could be a differential expression of molecules involved in the recognition of parasite structures. An example is TLR-2, more expressed by $\mathrm{BALB} / \mathrm{c}$ than by $\mathrm{C} 57 \mathrm{BL} / 6$ mice (35). It has been demonstrated that TLR-2 signaling induces IL-27 production by respiratory epithelial cells (36). Therefore, this natural high expression of TLR-2 by BALB/c may favor the IL-27 increase early after infection, lowering inflammation, and promoting infection.

We exploited the IL-27 dichotomy in BALB/c and C57BL/6 mice to study the role of this cytokine during the early steps of infection, using an in vivo artificial-modulation approach. The resulting data revealed a relation between the levels of IL-27 and infection establishment, as the neutralization or the supply of IL-27 resulted in decreased or increased parasite burdens, respectively. In addition, the administration of rIL-27 significantly increased the production of IL-10 while decreased IFN- $\gamma$ and IL-12p70 in the peritoneal cavity of C57BL/6 mice. Furthermore, the analysis of the cytokine production by splenic $\mathrm{T}$ cells revealed that IL-27 neutralization in BALB/c temporarily increased the numbers of IFN- $\gamma$ producing $\mathrm{CD} 4^{+}$and $\mathrm{CD} 8^{+}$ $\mathrm{T}$ cells. These results partially explain the higher parasite burdens quantified in the presence of IL-27. Addition of IL-27 in vitro exacerbates the infection of human macrophages by Leishmania amazonensis via IL-10 (11) and combined production of IL-27 and IL-10 by $L$. donovani-infected DCs is essential for IL-10 production by Th1 cells, resulting in parasite persistence (13). A recent work in $\mathrm{EBI}^{-1-}$ mice suggested a role for IL-27 in controlling IL-17 production and neutrophil infiltration during the chronic phase of $L$. infantum infection (30). However, whether the absence of the EBI3 subunit has an impact early after infection was not addressed in this work. We can also suggest that the IL-27 produced in response to infection shall not be a product of inflammation as $\mathrm{BALB} / \mathrm{c}$ mice present higher parasite loads than $\mathrm{C} 57 \mathrm{BL} / 6$ during the first days of infection, a difference that is counteracted by the treatments. Probably, the initial immune response of $\mathrm{BALB} / \mathrm{c}$ is less inflammatory and less capable of limiting infection installation, suggesting again that the parasites directly induce the production of IL-27 for their own benefit. In fact, the absence of IL-27 can also prevent mycobacterial-induced phagosomal maturation arrest, favoring the elimination of the intracellular pathogen by macrophages depending on IFN- $\gamma$ (37). In addition, IL-27 can impair the 
protective immunity to Mycobacterium tuberculosis in mice, as WSX-1 deficient T cells accumulate more efficiently in the lesions, showing improved capacity to produce IL-2 and reduced expression of cell death markers (25), functions that may also be altered during Leishmania infection.

Altogether, our data demonstrate that IL-27 increases after L. infantum infection both in humans and in animal models. These results confirm the involvement of IL-27 in mice models of Leishmania visceral pathogenesis, limiting inflammation during the initial stages of the infection and favoring parasite persistence, suggesting that the presence of IL-27 early after infection could influence the host immune response and the progression of the disease. Finally, we would like to highlight that IL-27 has the potential to be a useful biomarker for active human VL and for treatment efficacy monitoring, independently of the etiological agent and the geographical region affected.

\section{AUTHOR CONTRIBUTIONS}

BP-C, RS, and AC-d-S conceived and designed the experiments; BP-C, PC, AR, and EC performed the experiments; BP-C, PC, RS, EC, JM, JVM, RV, and AC-d-S analyzed the data; JM and AC-d-S contributed with reagents/materials/analysis tools; and BP-C, PC, $\mathrm{RV}$, and AC-d-S wrote the paper.

\section{REFERENCES}

1. Institute for Health Metrics and Evaluation (IHME). Age-Sex Specific AllCause and Cause-Specific Mortality 1990-2013. Global Burden of Disease Study 2013. Seattle, WA: GBD Publications (2014).

2. WHO. Leishmaniasis Fact Sheet $N^{\circ} 375$. (2015). Available from: http://www. who.int/mediacentre/factsheets/fs375/en/

3. Gollob KJ, Viana AG, Dutra WO. Immunoregulation in human American leishmaniasis: balancing pathology and protection. Parasite Immunol (2014) 36(8):367-76. doi:10.1111/pim.12100

4. Cecilio P, Perez-Cabezas B, Santarem N, Maciel J, Rodrigues V, Cordeiro da Silva A. Deception and manipulation: the arms of Leishmania, a successful parasite. Front Immunol (2014) 5:480. doi:10.3389/fimmu.2014.00480

5. Aparicio-Siegmund S, Garbers C. The biology of interleukin-27 reveals unique pro- and anti-inflammatory functions in immunity. Cytokine Growth Factor $\operatorname{Rev}$ (2015) 26(5):579-86. doi:10.1016/j.cytogfr.2015.07.008

6. Yoshida H, Hunter CA. The immunobiology of interleukin-27. Annu Rev Immunol (2015) 33:417-43. doi:10.1146/annurev-immunol-032414112134

7. Ansari NA, Kumar R, Gautam S, Nylen S, Singh OP, Sundar S, et al. IL-27 and IL-21 are associated with T cell IL-10 responses in human visceral leishmaniasis. J Immunol (2011) 186(7):3977-85. doi:10.4049/jimmunol. 1003588

8. Dos Santos PL, de Oliveira FA, Santos ML, Cunha LC, Lino MT, de Oliveira MF, et al. The severity of visceral leishmaniasis correlates with elevated levels of serum IL-6, IL-27 and sCD14. PLoS Negl Trop Dis (2016) 10(1):e0004375. doi:10.1371/journal.pntd.0004375

9. Anderson CF, Stumhofer JS, Hunter CA, Sacks D. IL-27 regulates IL-10 and IL-17 from CD4+ cells in nonhealing Leishmania major infection. J Immunol (2009) 183(7):4619-27. doi:10.4049/jimmunol.0804024

10. Rosas LE, Satoskar AA, Roth KM, Keiser TL, Barbi J, Hunter C, et al. Interleukin-27R (WSX-1/T-cell cytokine receptor) gene-deficient mice display enhanced resistance to Leishmania donovani infection but develop severe liver immunopathology. Am J Pathol (2006) 168(1):158-69. doi:10.2353/ ajpath.2006.050013

11. Barreto-de-Souza V, Ferreira PL, Vivarini Ade C, Calegari-Silva T, Soares DC, Regis EG, et al. IL-27 enhances Leishmania amazonensis infection via

\section{ACKNOWLEDGMENTS}

We thank Dr. Catarina Leitão (Flow cytometry unit, IBMC) and Dr. Sofia Lamas (Animal facilities, IBMC) for all the technical assistance.

\section{FUNDING}

This work was supported by Fundação para a Ciência e Tecnologia (FCT)/Ministério da Educação e da Ciência (MEC), co-funded by FEDER under the PT2020 Partnership Agreement through the Research Unit NO. 4293; by European Community's Seventh Framework Programme under grant agreement No. 603182 (Project MuLeVaClin) and by the ISCIII-AES project (project reference PI13/00440). PC and BP-C are supported by fellowships from the European Community's Seventh Framework Programme under grant agreements No. 603182 (Project MuLeVaClin) and No. 603240-2 (Project NMTryPI), respectively.

\section{SUPPLEMENTARY MATERIAL}

The Supplementary Material for this article can be found online at http://journal.frontiersin.org/article/10.3389/fimmu. 2016.00478/full\#supplementary-material.

ds-RNA dependent kinase (PKR) and IL-10 signaling. Immunobiology (2015) 220(4):437-44. doi:10.1016/j.imbio.2014.11.006

12. Artis D, Johnson LM, Joyce K, Saris C, Villarino A, Hunter CA, et al. Cutting edge: early IL-4 production governs the requirement for IL-27-WSX-1 signaling in the development of protective Th1 cytokine responses following Leishmania major infection. J Immunol (2004) 172(8):4672-5. doi:10.4049/ jimmunol.172.8.4672

13. Owens BM, Beattie L, Moore JW, Brown N, Mann JL, Dalton JE, et al. IL-10-producing Th1 cells and disease progression are regulated by distinct CD11c(+) cell populations during visceral leishmaniasis. PLoS Pathog (2012) 8(7):e1002827. doi:10.1371/journal.ppat.1002827

14. Smedsrod B, Pertoft H. Preparation of pure hepatocytes and reticuloendothelial cells in high yield from a single rat liver by means of Percoll centrifugation and selective adherence. J Leukoc Biol (1985) 38(2):213-30.

15. Neves BM, Silvestre R, Resende M, Ouaissi A, Cunha J, Tavares J, et al. Activation of phosphatidylinositol 3-kinase/Akt and impairment of nuclear factor-kappaB: molecular mechanisms behind the arrested maturation/ activation state of Leishmania infantum-infected dendritic cells. Am J Pathol (2010) 177(6):2898-911. doi:10.2353/ajpath.2010.100367

16. Zal T, Volkmann A, Stockinger B. Mechanisms of tolerance induction in major histocompatibility complex class II-restricted T cells specific for a blood-borne self-antigen. J Exp Med (1994) 180(6):2089-99. doi:10.1084/jem. 180.6.2089

17. Fujita H, Teng A, Nozawa R, Takamoto-Matsui Y, Katagiri-Matsumura H, Ikezawa Z, et al. Production of both IL-27 and IFN-gamma after the treatment with a ligand for invariant NK T cells is responsible for the suppression of Th2 response and allergic inflammation in a mouse experimental asthma model. J Immunol (2009) 183(1):254-60. doi:10.4049/jimmunol.0800520

18. Vasconcellos R, Carter NA, Rosser EC, Mauri C. IL-12p35 subunit contributes to autoimmunity by limiting IL-27-driven regulatory responses. J Immunol (2011) 187(6):3402-12. doi:10.4049/jimmunol.1100224

19. Silvestre R, Cordeiro-Da-Silva A, Santarem N, Vergnes B, Sereno D, Ouaissi A. SIR2-deficient Leishmania infantum induces a defined IFN-gamma/IL-10 pattern that correlates with protection. J Immunol (2007) 179(5):3161-70. doi:10.4049/jimmunol.179.5.3161

20. do Vale A, Afonso A, Silva MT. The professional phagocytes of sea bass (Dicentrarchus labrax L.): cytochemical characterisation of neutrophils and 
macrophages in the normal and inflamed peritoneal cavity. Fish Shellfish Immunol (2002) 13(3):183-98. doi:10.1006/fsim.2001.0394

21. Resende M, Moreira D, Augusto J, Cunha J, Neves B, Cruz MT, et al. Leishmania-infected MHC class IIhigh dendritic cells polarize CD4+ T cells toward a nonprotective T-bet+ IFN-gamma+ IL-10+ phenotype. J Immunol (2013) 191(1):262-73. doi:10.4049/jimmunol.1203518

22. Maroof A, Kaye PM. Temporal regulation of interleukin-12p70 (IL-12p70) and IL-12-related cytokines in splenic dendritic cell subsets during Leishmania donovani infection. Infect Immun (2008) 76(1):239-49. doi:10.1128/IAI.00643-07

23. Zhu C, Zhang R, Liu L, Rasool ST, Mu Y, Sun W, et al. Hepatitis B virus enhances interleukin-27 expression both in vivo and in vitro. Clin Immunol (2009) 131(1):92-7. doi:10.1016/j.clim.2008.10.011

24. Liu L, Cao Z, Chen J, Li R, Cao Y, Zhu C, et al. Influenza A virus induces interleukin-27 through cyclooxygenase-2 and protein kinase A signaling. J Biol Chem (2012) 287(15):11899-910. doi:10.1074/jbc.M111. 308064

25. Torrado E, Fountain JJ, Liao M, Tighe M, Reiley WW, Lai RP, et al. Interleukin $27 \mathrm{R}$ regulates $\mathrm{CD} 4+\mathrm{T}$ cell phenotype and impacts protective immunity during Mycobacterium tuberculosis infection. JExp Med (2015) 212(9):1449-63. doi:10.1084/jem.20141520

26. Novoa $R$, Bacellar $O$, Nascimento $M$, Cardoso TM, Ramasawmy $R$, Oliveira WN, et al. IL-17 and regulatory cytokines (IL-10 and IL-27) in L. braziliensis infection. Parasite Immunol (2011) 33(2):132-6. doi:10.1111/ j.1365-3024.2010.01256.x

27. Tolouei S, Ghaedi K, Khamesipour A, Akbari M, Baghaei M, Hasheminia S, et al. IL-23 and IL-27 levels in macrophages collected from peripheral blood of patients with healing vs non-healing form of cutaneous leishmaniasis. Iran J Parasitol (2012) 7(1):18-25.

28. Costa DL, Cardoso TM, Queiroz A, Milanezi CM, Bacellar O, Carvalho EM, et al. Tr-1-like CD4+CD25-CD127-/lowFOXP3- cells are the main source of interleukin 10 in patients with cutaneous leishmaniasis due to Leishmania braziliensis. J Infect Dis (2015) 211(5):708-18. doi:10.1093/infdis/ jiu406

29. Sandquist M, Wong HR. Biomarkers of sepsis and their potential value in diagnosis, prognosis and treatment. Expert Rev Clin Immunol (2014) 10(10):1349-56. doi:10.1586/1744666X.2014.949675

30. Quirino GF, Nascimento MS, Davoli-Ferreira M, Sacramento LA, Lima MH, Almeida RP, et al. Interleukin-27 mediates susceptibility to visceral leishmaniasis by suppressing the IL-17-neutrophil response. Infect Immun (2016) 84(8):2289-98. doi:10.1128/IAI.00283-16
31. Wang RX, Yu CR, Dambuza IM, Mahdi RM, Dolinska MB, Sergeev YV, et al. Interleukin-35 induces regulatory B cells that suppress autoimmune disease. Nat Med (2014) 20(6):633-41. doi:10.1038/nm.3554

32. Lipoldova M, Demant P. Genetic susceptibility to infectious disease: lessons from mouse models of leishmaniasis. Nat Rev Genet (2006) 7(4):294-305. doi: $10.1038 / \operatorname{nrg} 1832$

33. Blahoianu MA, Rahimi AAR, Kozlowski M, Angel JB, Kumar A. IFN- $\gamma$ induced IL-27 and IL-27p28 expression are differentially regulated through JNK MAPK and PI3K pathways independent of Jak/STAT in human monocytic cells. Immunobiology (2014) 219(1):1-8. doi:10.1016/j.imbio. 2013.06.001

34. Zhang S, Liang R, Luo W, Liu C, Wu X, Gao Y, et al. High susceptibility to liver injury in IL-27 p28 conditional knockout mice involves intrinsic interferon- $\gamma$ dysregulation of CD4+ T cells. Hepatology (2013) 57(4):1620-31. doi:10.1002/ hep. 26166

35. Huang L, Hinchman M, Mendez S. Coinjection with TLR2 agonist Pam3CSK4 reduces the pathology of leishmanization in mice. PLoS Negl Trop Dis (2015) 9(3):e0003546. doi:10.1371/journal.pntd.0003546

36. Kim HS, Go H, Akira S, Chung DH. TLR2-mediated production of IL-27 and chemokines by respiratory epithelial cells promotes bleomycin-induced pulmonary fibrosis in mice. J Immunol (2011) 187(8):4007-17. doi:10.4049/ jimmunol.1101654

37. Jung JY, Robinson CM. IL-12 and IL-27 regulate the phagolysosomal pathway in mycobacteria-infected human macrophages. Cell Commun Signal (2014) 12:16. doi:10.1186/1478-811X-12-16

Conflict of Interest Statement: The authors declare that the research was conducted in the absence of any commercial or financial relationships that could be construed as a potential conflict of interest.

The reviewer CL and handling editor declared their shared affiliation, and the handling editor states that the process nevertheless met the standards of a fair and objective review.

Copyright (๑) 2016 Pérez-Cabezas, Cecílio, Robalo, Silvestre, Carrillo, Moreno, San Martín, Vasconcellos and Cordeiro-da-Silva. This is an open-access article distributed under the terms of the Creative Commons Attribution License (CC BY). The use, distribution or reproduction in other forums is permitted, provided the original author(s) or licensor are credited and that the original publication in this journal is cited, in accordance with accepted academic practice. No use, distribution or reproduction is permitted which does not comply with these terms. 